\title{
Chromium-modified zinc oxides
}

\author{
Wojciech Gac $^{1} \cdot$ Witold Zawadzki $^{1} \cdot$ Grzegorz Słowik $^{1} \cdot$ Magdalena Greluk $^{1}$ • \\ Justyna Pawlonka ${ }^{1}$ Andrzej Machocki ${ }^{1}$
}

Received: 10 November 2015/Accepted: 21 May 2016/Published online: 18 June 2016

(c) The Author(s) 2016. This article is published with open access at Springerlink.com

\begin{abstract}
Zinc oxides modified with chromium were prepared by the co-precipitation method. Samples were calcined at $400{ }^{\circ} \mathrm{C}$. Structural and surface properties of materials were studied by means of transmission electron microscopy, X-ray diffraction and low-temperature nitrogen adsorption methods. Temperature-programmed reduction methods were used for investigation of the influence of chromium on the redox properties of zinc oxides. The nature of surface sites and the course of surface reactions occurred during methanol decomposition were determined by the temperature-programmed desorption of methanol with detection of evolved gasses by mass spectrometry and in situ diffuse reflectance infrared Fourier transform spectroscopy. We have found that modification of $\mathrm{ZnO}$ with chromium led to the increase of the specific surface area of oxides and decrease of mean crystallite size of $\mathrm{ZnO}$. Partial incorporation of chromium ions to the hexagonal $\mathrm{ZnO}$ structure, formation of strongly dispersed spinel $\left(\mathrm{ZnCr}_{2} \mathrm{O}_{4}\right)$ and chromium zinc oxide species $\left(\mathrm{ZnO} \cdot \mathrm{CrO}_{3}\right)$ was observed. We have stated that methanol was adsorbed on the surface of $\mathrm{ZnO}$ at $100{ }^{\circ} \mathrm{C}$ mainly via formation of methoxy species, and the main products of methanol desorption were carbon monoxide and hydrogen. The presence of chromium facilitated direct oxidation of methoxy groups to formate species at low temperatures $\left(\sim 100^{\circ} \mathrm{C}\right)$ and their transformation to hydrogen and carbon dioxide during temperature-programmed desorption. The enhanced transformation of
\end{abstract}

Wojciech Gac

wojciech.gac@umcs.lublin.pl

1 Department of Chemical Technology, Faculty of Chemistry, Maria Curie-Sklodowska University, 3 M. Curie-Sklodowska Sq., 20-031 Lublin, Poland methoxy to formate species was attributed to the labile oxygen in chromium-modified zinc oxides.

Keywords Zinc oxide - Chromium · Methanol desorption · TPR · TPD · DRIFTS

\section{Introduction}

Zinc oxide has been widely used in rubber industry, production of ceramics, concrete, cosmetics and personal care, surface coatings, pharmaceuticals and foods [1]. An increase of the interests of application of $\mathrm{ZnO}$ in the emerging technologies is observed [2, 3]. Zinc oxide has been proposed for the production of light-emitting and laser diodes [4, 5], varistors [6], sensors [7, 8], magnetic materials [9] and photocatalysts [10]. This oxide has been used as an adsorbent for purification of gas streams and component of industrial catalysts, mainly for hydrogenation and dehydrogenation reactions. Pure zinc oxide shows relatively low thermal stability. The increase of the specific surface area and retardation of sintering of $\mathrm{ZnO}$ particles have been often achieved by the introduction of additional metal oxides. Modification of $\mathrm{ZnO}$, especially for rubber production, has been often reached by functionalization of the surface of $\mathrm{ZnO}$ particles with silica, alumina, siloxane groups, deposition of organic and polymeric protecting layers [11]. In 1923, BASF introduced zinc oxide/chromium oxide catalysts for high-pressure methanol synthesis [12]. The catalysts were obtained by mixing of chromic acid with an aqueous suspension of zinc hydroxide or in simpler way, by mixing of zinc oxide powder with chromic oxide. In the next years, the catalysts based on the mixtures of oxides or made by co-precipitation of soluble zinc and chromium salts were developed and offered by BASF, Du 
Pont, Montedison, ICI [12]. High activity in methanol synthesis has been observed for $\mathrm{Cu} / \mathrm{ZnO}$ catalysts since 1930s of the last century. However, such catalysts suffered from rapid deactivation due to sintering. The breakthrough in methanol synthesis (resulted further in the development of low-pressure methanol plants) was done in the 1960s by modification of $\mathrm{Cu} / \mathrm{ZnO}$ catalysts with promoters, such as the oxides of $\mathrm{Al}, \mathrm{Cr}$ or $\mathrm{Mn}$. Similar $\mathrm{CuO} / \mathrm{ZnO}$ catalysts, modified with alumina or chromium oxide, were used for water gas shift reaction (WGS) in ammonia synthesis plants. The beneficial properties of such catalysts were mainly ascribed to the presence of zinc aluminate or chromite spinels, which improved stability of zinc oxide. In spite of large efforts and a reach literature, further studies are necessary to better understand the nature of catalytic active sites and develop new catalysts.

The improvement of zinc oxide-based catalysts is today of vital importance. Zinc oxide has been recently proposed for numerous reactions, including desulfurization, transesterification of vegetable oils and fine chemical synthesis $[13,14]$. Besides methanol synthesis and water gas shift reaction, two additional processes become today of prime interests, i.e. carbon dioxide conversion with hydrogen to methanol and steam reforming of methanol $[15,16]$. Carbon dioxide is produced worldwide via combustion of fossil fuels. The increase of global temperature is perceived as result of increase of $\mathrm{CO}_{2}$ concentration in atmosphere from $300 \mathrm{ppm}$ on the pre-industrial level to nearly $400 \mathrm{ppm}$. Synthesis of methanol from $\mathrm{CO}_{2}$, which could be captured from the fossil fuel combustion processes, and hydrogen obtained by the use of renewable energy is regarded as one of the most promising ways of carbon capture and utilization technologies [17]. Methanol is produced today in the large scale by conversion of carbon monoxide with hydrogen adding small amounts of carbon dioxide, mainly in the presence of modified copper zinc oxide catalysts. New catalysts for direct conversion of carbon dioxide with hydrogen to methanol can be obtained by the application of new improved supports, such as chromium-modified zinc oxides, and hence, better understanding of surface phenomena is indispensable. In turn, hydrogen can be produced on-site in the small stationary or portable systems by the steam reforming of methanol. The main reaction products of this reaction are hydrogen and carbon dioxide. Such mixture after removal of the traces of carbon monoxide can be used in the low-temperature proton exchange membrane fuel cells (PEMFC) or even directly in the Internal Reforming Methanol Fuel Cell (IRMFC) for electricity production [18]. Better insight into the properties of chromium-modified zinc oxide supports may bring progress in the development of new catalysts for the steam reforming of methanol. Such catalysts should show high activity, low selectivity to carbon monoxide, high durability and thermal stability in transient conditions.

The aim of the studies was the synthesis of novel chromium-modified zinc oxide materials, elucidation of the role of chromium on the structural, surface and redox properties of the samples and determination of the course of surface reactions during methanol desorption with regard to the potential application of such oxide materials as the supports and/or catalysts for $\mathrm{CO}_{2}$ hydrogenation and steam reforming of methanol.

\section{Experimental}

\section{Sample preparation}

Zinc oxide was prepared by the precipitation method. Zinc acetate $\left(\mathrm{Zn}\left(\mathrm{CH}_{3} \mathrm{COO}\right)_{2} \cdot 2 \mathrm{H}_{2} \mathrm{O}\right)$ was dissolved in distilled water and precipitated with aqueous solution of ammonium carbonate $\left(\left(\mathrm{NH}_{4}\right)_{2} \mathrm{CO}_{3}\right)$. The precipitating agent was slowly introduced with the constant rate to $\mathrm{pH}=8.5$. The mixture was then filtered under vacuum and flushed with water and ethanol. The sample was dried at $120{ }^{\circ} \mathrm{C}$ and calcined at $400{ }^{\circ} \mathrm{C}$ for $6 \mathrm{~h}$. Chromium-modified zinc oxides (denoted as $\mathrm{ZnO}-\mathrm{Cr}-\mathrm{x}$ ) were obtained by the co-precipitation method. Suitable amounts of zinc acetate $\left(\mathrm{Zn}\left(\mathrm{CH}_{3} \mathrm{COO}\right)_{2} \cdot 2 \mathrm{H}_{2} \mathrm{O}\right)$ and chromium nitrate $\left(\mathrm{Cr}\left(\mathrm{NO}_{3}\right)_{3-}\right.$ $9 \mathrm{H}_{2} \mathrm{O}$ ) were dissolved in distilled water and then co-precipitated with aqueous solution of ammonium carbonate in the same conditions as above. Next similar procedures of filtering, drying and calcination as in the synthesis of unmodified $\mathrm{ZnO}$ were applied.

\section{Experimental techniques}

X-ray diffraction studies (XRD) were done with Empyrean (PANalytical) diffractometer using $\mathrm{Cu}-\mathrm{K}_{\alpha}$ radiation ( $\lambda=1.5418 \AA$ ). A standard procedure of profile fitting analysis was performed using HighScore Plus program, which included: background determination, peak searching, profile fitting and overlapping peaks deconvolution, Kalpha2 peaks removing and determination of width at half maximum (FWHM) of selected deconvoluted peaks. Mean size of $\mathrm{ZnO}$ crystallites $\left(d_{x}\right)$ was calculated from the broadening of the deconvoluted $\mathrm{ZnO}$ XRD peaks using the Warren-Scherrer equation [19]:

$d_{x}=\frac{0.9 \lambda}{\left(B_{1}^{2}-B_{2}^{2}\right)^{1 / 2} \cos \theta}$

where $\theta$, diffraction angle; $\lambda, \mathrm{X}$-ray wavelength (1.54179 $\AA$ for $\mathrm{Cu}$ lamp); $B_{1}$, peak width at half maximum (FWHM) of the reflection; and $B_{2}$, peak width of the 
standard. The discussion was based on the results for $\mathrm{ZnO}$ (110) peak due to its high intensity and relatively small effects of other phases.

The nitrogen adsorption/desorption isotherms were obtained volumetrically at $-196{ }^{\circ} \mathrm{C}$ using ASAP $2405 \mathrm{~N}$ analyzer (Micromeritics Instrument Corp.). Samples were outgassed under low pressure $\left(\sim 10^{-2} \mathrm{~Pa}\right)$ at $200{ }^{\circ} \mathrm{C}$. The adsorption data were used to evaluate the specific surface area $\left(S_{\mathrm{BET}}\right)$. The total pore volume $\left(V_{\mathrm{p}}\right)$ was determined on the basis of nitrogen amount adsorbed at relative pressure of about $p / p^{\circ}=0.98$. Keeping in mind some limitation of different models, the structural data were estimated from the adsorption branch of isotherms by applying the BarrettJoyner-Halenda (BJH) method [20].

The samples for microscopic studies were grinded in an agate mortar to a fine powder. The resulting powder was poured with absolute ethanol to form a slurry. The sample was inserted into the ultrasonic homogenizer for $20 \mathrm{~s}$. Then, the slurry was introduced to a copper grid covered with formvar stabilized with carbon. The sample was left on the filter paper until ethanol was evaporated. The transmission electron microscope Titan G2 60-300 kV FEI Company with an accelerating voltage of the electron beam equal to $300 \mathrm{kV}$ was used in the studies of the samples by the scanning transmission electron microscopy-energydispersive X-ray spectroscopy technique (STEM-EDX). The transmission electron microscopic studies (TEM) of the samples were carried out with TEM microscope Tecnai G20 X-TWIN FEI Company using an accelerating voltage of the electron beam equal to $200 \mathrm{kV}$.

Redox properties of materials were investigated by the temperature-programmed reduction (TPR) and reduction/ oxidation methods (TPR/TPO/TPR). Studies were carried out in the TPR apparatus Autochem 2920 (Micromeritics Instrument Corp.). Samples $(m=0.05 \mathrm{~g})$ in the TPR studies were initially heated in the flow of helium up to $150{ }^{\circ} \mathrm{C}$ and after $30 \mathrm{~min}$ of isothermal treatment were cooled down to $-70{ }^{\circ} \mathrm{C}$. The reduction was performed in the flow of the mixture $5 \mathrm{vol} \% \mathrm{H}_{2}$ in $\operatorname{Ar}\left(Q=30 \mathrm{~cm}^{3} \mathrm{~min}^{-1}\right)$ up to $600{ }^{\circ} \mathrm{C}$ with linear ramp rate $10^{\circ} \mathrm{C} \mathrm{min}{ }^{-1}$. The evolved water was removed from the stream of carrier gas in a cold trap with the $\mathrm{LN}_{2}$-isopropanol mixture at $-77^{\circ} \mathrm{C}$, maintained between reactor and thermal conductivity detector (TCD). Samples in the TPR/TPO/TPR experiments after similar pre-treatment procedure as in TPR studies were reduced with linear ramp rate $10{ }^{\circ} \mathrm{C} \mathrm{min}^{-1}$ from -70 to $350{ }^{\circ} \mathrm{C}$ and then at $350{ }^{\circ} \mathrm{C}$ for $1 \mathrm{~h}$ (TPR-1). The samples were next cooled down to $-70{ }^{\circ} \mathrm{C}$ in the flow of He. The inert gas was then switched for the mixture $5 \mathrm{vol} \%$ of $\mathrm{O}_{2}$ in He $\left(Q=30 \mathrm{~cm}^{3} \mathrm{~min}^{-1}\right)$, and the samples were oxidized under the linear ramp rate $10^{\circ} \mathrm{C} \min ^{-1}$ up to $100{ }^{\circ} \mathrm{C}$. The oxidizing mixture after $1 \mathrm{~h}$ was changed to $\mathrm{He}$, and the temperature was decreased to $-70{ }^{\circ} \mathrm{C}$. Next the reduction- oxidation procedures were repeated, while oxidation temperature was successively increased to $200,300{ }^{\circ} \mathrm{C}$ and finally to $400{ }^{\circ} \mathrm{C}$.

Methanol temperature-programmed desorption studies (TPD-MS) were carried out in the reaction system coupled with mass spectrometer HAL201RC (Hiden Analytical). The samples were initially heated in the flow of He up to $350{ }^{\circ} \mathrm{C}$ and then after $1 \mathrm{~h}$ were cooled down to $100{ }^{\circ} \mathrm{C}$. Methanol was adsorbed at $100{ }^{\circ} \mathrm{C}$ from the $\mathrm{He}$ stream, which was passed through methanol saturator maintained at $15^{\circ} \mathrm{C}$. The samples, after flushing with $\mathrm{He}$, were heated with $10{ }^{\circ} \mathrm{C} \mathrm{min}^{-1}$ ramp rare. The MS intensities of selected ions were recorded. The nature of the species formed on the surface of oxides during methanol temperatureprogrammed desorption was studied by diffuse reflectance infrared Fourier transform spectroscopy (DRIFTS). The samples were subjected to the same procedures as in the TPD-MS studies, using Ar as carrier gas. FTIR spectrometer (Nicolet 6700, Thermo Scientific) was equipped with $\mathrm{LN}_{2}$ cooled MCT/A detector. Samples were introduced into the Praying Mantis High-Temperature Reaction Chamber (Harrick), which was covered by a dome with ZnSe windows. DRIFTS spectra were collected during Ar pre-treatment, methanol adsorption and desorption at selected temperatures with the resolution of $4 \mathrm{~cm}^{-1}$ and maximum source aperture. Interferograms of 256 scans were averaged for each spectrum. The spectra were corrected by applying the background signal recorded for $\mathrm{KBr}$ powder.

\section{Results and discussion}

\section{Phase composition}

The content of chromium in modified zinc oxides was varied from 3.33 to 17.1 mass $\%$ (Table 1). The results of $\mathrm{X}$-ray diffraction studies of the samples are presented in Fig. 1. $\mathrm{ZnO}$ hexagonal structure with the space group $C_{6 \mathrm{v}}^{4}-P 6_{3} \mathrm{mc}$ (ICDD: $\mathrm{ZnO}-04-008-8199$ ) is observed in the unmodified and chromium-modified oxide materials. The mean crystallite size decreases from $23 \mathrm{~nm}$ in $\mathrm{ZnO}$ sample to $5.1 \mathrm{~nm}$ in $\mathrm{ZnO}-\mathrm{Cr}-3$ sample (Table 1). Gradual broadening of $\mathrm{ZnO}$ peaks with the increase of chromium content indicates the decrease of the size of $\mathrm{ZnO}$ particles. The diffraction peaks of zinc oxide in $\mathrm{ZnO}-\mathrm{Cr}-\mathrm{x}$ samples are located at slightly higher diffraction angles than pure $\mathrm{ZnO}$. Gradual shift is observed with an increase of chromium content (Table 1). Such changes could result from the reduction in lattice constant and decrease of the volume of the unit cell. The lattice contraction could be ascribed to the variation of the surface stresses, due to the crystallite size decrease [21]. Other possible explanation is partial 
Table 1 Specific surface area $\left(S_{\mathrm{BET}}\right)$, total pore volume $\left(V_{\mathrm{p}}\right)$, mean pore diameter $\left(D_{\mathrm{p}}\right)$ of the samples, mean crystallite size $\left(d_{\mathrm{x}}\right)$ of $\mathrm{ZnO}$ and position of XRD (110) reflection lines of $\mathrm{ZnO}$

\begin{tabular}{lllllll}
\hline Sample & Cr content/wt $\%$ & $S_{\mathrm{BET}} / \mathrm{m}^{2} \mathrm{~g}^{-1}$ & $V_{\mathrm{p}} / \mathrm{cm}^{3} \mathrm{~g}^{-1}$ & $D_{\mathrm{p}} / \mathrm{nm}$ & $d_{\mathrm{x}} / \mathrm{nm}$ & $\mathrm{XRD}(110)(2 \theta)$ \\
\hline $\mathrm{ZnO}$ & - & 35.7 & 0.41 & 41.5 & 23.0 & 56.52 \\
$\mathrm{ZnO}-\mathrm{Cr}-1$ & $3.33 \pm 0.15$ & 45.2 & 0.21 & 0.35 & 17.3 & 56.53 \\
$\mathrm{ZnO}-\mathrm{Cr}-2$ & $13.00 \pm 0.50$ & 94.6 & 0.16 & 10.0 & 5.3 & 5.1 \\
$\mathrm{ZnO}-\mathrm{Cr}-3$ & $17.10 \pm 0.50$ & 73.1 & & & 56.61 & 5.82 \\
\hline
\end{tabular}

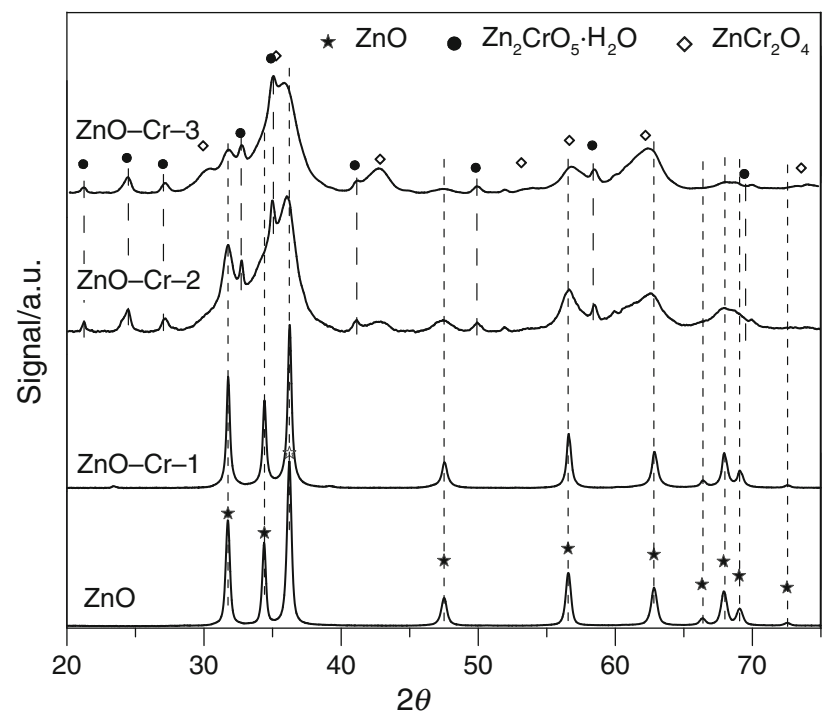

Fig. 1 XRD patterns of the samples

substitution of zinc ions in $\mathrm{ZnO}$ structure by smaller chromium ions. The effective ionic radius of $\mathrm{Zn}^{2+}$ is $0.74 \AA$, while the radius of $\mathrm{Cr}^{3+}$ equals $0.61 \AA$ [22]. This may facilitate formation of point defects in $\mathrm{ZnO}$ structure, generation of $\mathrm{Zn}^{2+}$ vacancies and non-stoichiometry and hence alter the surface and catalytic properties of the materials used as the supports or catalysts.

XRD diffraction studies reveal the presence of dispersed zinc chromium oxide species. It is hard to unambiguously ascribe the peaks to the singular phase. The XRD peaks can be assigned to different oxide materials of $\mathrm{Zn}^{2+}, \mathrm{Cr}^{3+}$ or $\mathrm{Cr}^{6+}$, including spinel $\mathrm{ZnCr}_{2} \mathrm{O}_{4}$ (ICDD: $\mathrm{ZnCr}_{2} \mathrm{O}_{4}-01-079-$ 5291 ) and zinc chromium oxide phases of similar positions of reflection lines, including $4 \mathrm{ZnO} \cdot \mathrm{CrO}_{3} \bullet 3 \mathrm{H}_{2} \mathrm{O}$ (ICDD: 00011-0275), $2 \mathrm{ZnO} \cdot \mathrm{CrO}_{3} \bullet \mathrm{H}_{2} \mathrm{O}$ (ICDD: 00-011-0276) or $\mathrm{Zn}_{2} \mathrm{CrO}_{5}$ (ICDD: 00-011-0277). Precipitation of zinc and chromium compounds with ammonium carbonate can initially drive to the formation of layered double hydroxides (LDHs) with hydrotalcite-like (HT) structure [23-25]. LDHs of general formulae $\left[\mathrm{M}_{1-\mathrm{x}}^{2+} \mathrm{M}_{\mathrm{x}}^{3+}(\mathrm{OH})_{2}\right]^{\mathrm{x}+}\left[A_{\mathrm{x} / \mathrm{n}}^{\mathrm{n}-}\right]$. $\mathrm{mH}_{2} \mathrm{O}$ are composed of the divalent metal ions $\left(\mathrm{M}^{2+}\right)$ distributed within the layers containing trivalent metal ions $\left(\mathrm{M}^{3+}\right)$, separated by the layers of $\mathrm{A}^{\mathrm{n}-}$ anions with negative charge $n$ [23-25]. The value of $x$ is related to the molar ratio of $\mathrm{M}^{2+} /\left(\mathrm{M}^{2+}+\mathrm{M}^{2+}\right)$ and generally is in the range $0.2-0.33$. The intercalated anions maintain charge balance resulted from partial substitution of divalent by trivalent cations. Thermal treatment of hydrotalcite phases up to $200{ }^{\circ} \mathrm{C}$ leads initially to the dehydration of surface water and removal of crystallization water from interlayer regions [25]. The increase of treatment temperature up to $400{ }^{\circ} \mathrm{C}$ results in dehydroxylation and the loss of carbonate anions from the interlayer regions, which induce further structural changes of materials. Although HT structure can be retained in some oxide materials after calcination at $400{ }^{\circ} \mathrm{C}$ or recovered in contact with water and carbon dioxide, e.g. in $\mathrm{LDHs}$ containing $\mathrm{Mg}^{2+}$ or $\mathrm{Al}^{3+}$, we have not observed such phases in the obtained $\mathrm{ZnO}-\mathrm{Cr}$ samples. The presence of $\mathrm{ZnO} \cdot \mathrm{CrO}_{3}$ oxide phases results from oxidation of $\mathrm{Cr}^{3+}$ ions in calcination stage. The changes of the oxidation state of chromium ions during thermal treatment in air were reported in the literature for different hydrotalcite materials containing chromium [24-27]. Rives pointed out that $\mathrm{Cr}^{3+}$ in $\mathrm{ZnCr}$ hydotalcite materials can be oxidized to $\mathrm{CrO}_{4}^{-}$below $400{ }^{\circ} \mathrm{C}$ with formation of amorphous zinc hydroxychromates, while thermal treatment of materials at higher temperatures may lead to the decrease of oxidation state of $\mathrm{Cr}^{6+}$ and formation of $\mathrm{ZnCr}_{2} \mathrm{O}_{4}$ spinel [26]. Similar changes of chromium oxides at high temperature are discussed in Ref. [28]. $\mathrm{CrO}_{3}$ can be decomposed in air at elevated temperatures to the oxides of lower oxidation state, e.g. at $300{ }^{\circ} \mathrm{C}$ to $\mathrm{Cr}_{6} \mathrm{O}_{15}, 420{ }^{\circ} \mathrm{C}$ to $\mathrm{Cr}_{5} \mathrm{O}_{9}$ and at $450{ }^{\circ} \mathrm{C}$ to $\mathrm{Cr}_{2} \mathrm{O}_{3}$ [28]. $\mathrm{ZnO}$ support may stabilize chromium oxides on the lower oxidation state of chromium and participate in the formation of $\mathrm{ZnCr}_{2} \mathrm{O}_{4}$ spinel phases. $\mathrm{Zn}^{2+}$ ions in spinels, especially in $\mathrm{ZnCr}_{2} \mathrm{O}_{4}$ non-stoichiometric spinel, can be located both in tetrahedral and in octahedral environment [28]. Erranni pointed out that the presence of surface octahedral zinc ions, i.e. located in the non-stoichiometric spinels, is crucial for high activity of catalysts in methanol synthesis [29]. He suggested that such sites are responsible for heterolytic dissociative adsorption of hydrogen. 


\section{Structural changes}

The morphology and spatial distribution of elements in the samples obtained by STEM-EDX technique are presented in Fig. 2. STEM-EDX images of $\mathrm{ZnO}$ sample (Fig. 2a) show the assemblies of $\mathrm{ZnO}$ nanoparticles with elongated shape and uniform distribution of zinc and oxygen. An introduction of chromium induces structural changes and formation of much smaller nanoparticles. The nanoparticles in $\mathrm{ZnO}-\mathrm{Cr}-1$ are less regular than in the $\mathrm{ZnO}$ sample (Fig. 2b). An increase of chromium content leads to the increase of the amounts of amorphous-like phases. One can find irregular and rod-like agglomerates, composed of very small particles (Fig. 2c, d). Regular nanoparticles of $\mathrm{ZnO}$ are well visible on the TEM image (Fig. 3a). HRTEM image (see inset in Fig. 3a) reveals hexagonal arrangement of atoms in selected nanoparticle attached to the second one with different orientation. Particles of different size are well visible in the TEM image of $\mathrm{ZnO}-\mathrm{Cr}-1$ sample (Fig. 3b). $\mathrm{ZnO}-\mathrm{Cr}-2$ and $\mathrm{ZnO}-\mathrm{Cr}-3$ samples are composed of very small nanoparticles of different shape and orientation, which resemble amorphous-like phases observed in the STEM-EDX studies. The size of nanoparticles is below
$10 \mathrm{~nm}$. The results are similar to that obtained from XRD studies.

The specific surface area $\left(S_{\mathrm{BET}}\right)$ of the $\mathrm{ZnO}$ sample is $35.7 \mathrm{~m}^{2} \mathrm{~g}^{-1}$ (Table 1). An introduction of chromium led to the increase of the specific surface area and to the changes of porosity of materials (Table 1). The shape of nitrogen isotherms of the samples is in general similar (Fig. 4), and close to that of II-type, according to the IUPAC recommendations [30]. The shape of hysteresis loop for $\mathrm{ZnO}$ sample is close to $\mathrm{H} 3$ type and indicates the presence of slit-shaped pores. Such pores may result from the spatial arrangement of nanoparticles of uniform planes and close attachment of elongated agglomerates, well visible on the TEM images (Fig. 3a). In the case of chromium-modified oxides, the hysteresis loops are wider and are shifted to lower values of relative pressures, indicating different pore size distribution. Total pore volume $\left(V_{\mathrm{p}}\right)$ and mean pore diameter $\left(D_{\mathrm{p}}\right)$ of the $\mathrm{ZnO}$ sample are equal to $0.41 \mathrm{~cm}^{3} \mathrm{~g}^{-1}$ and $41.5 \mathrm{~nm}$, respectively. The decrease of total pore volume and mean pore diameter is observed with an increase of chromium content. High surface area or low crystallite size of the oxides could be obtained under optimal $\mathrm{Cr} / \mathrm{Zn}$ ratio and calcination temperature $[31,32]$. (a)

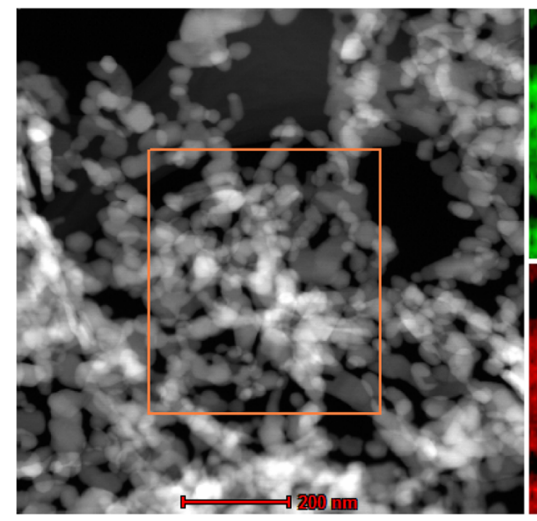

(c)

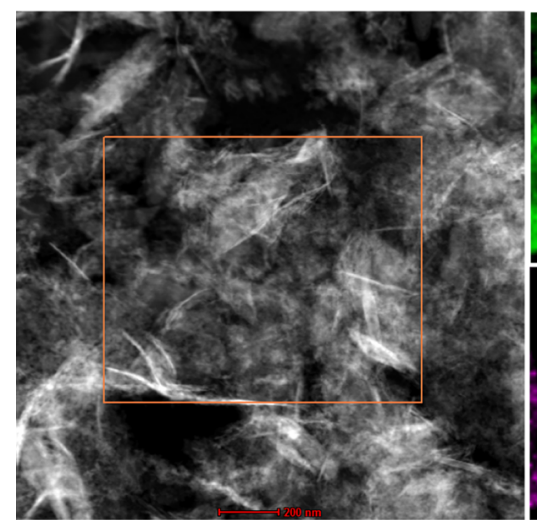

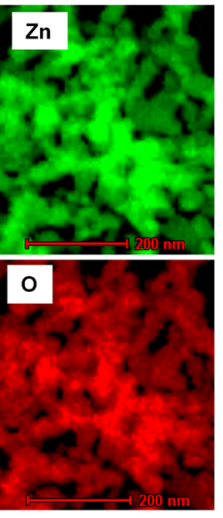

(b)

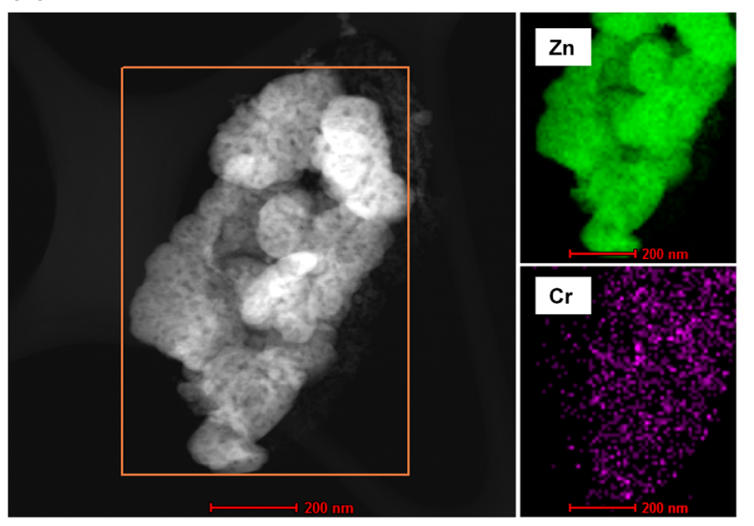

(d)

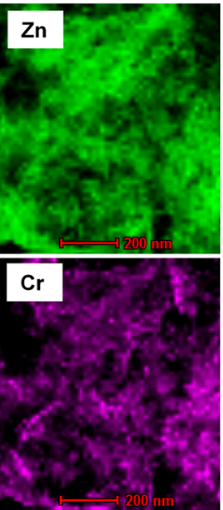

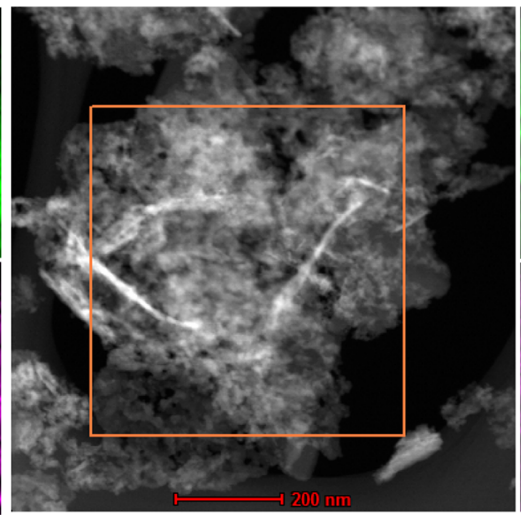

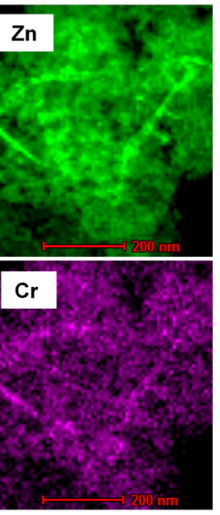

Fig. 2 STEM-EDX images of the samples: a $\mathrm{ZnO}$, b $\mathrm{ZnO}-\mathrm{Cr}-1$, c $\mathrm{ZnO}-\mathrm{Cr}-2$, d $\mathrm{ZnO}-\mathrm{Cr}-3$ 
(a)

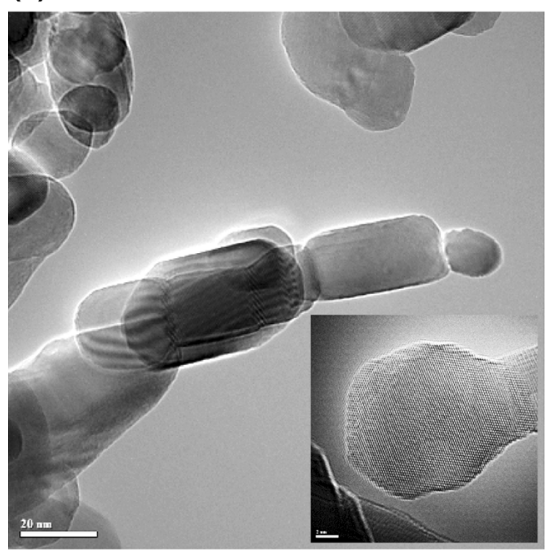

(c)

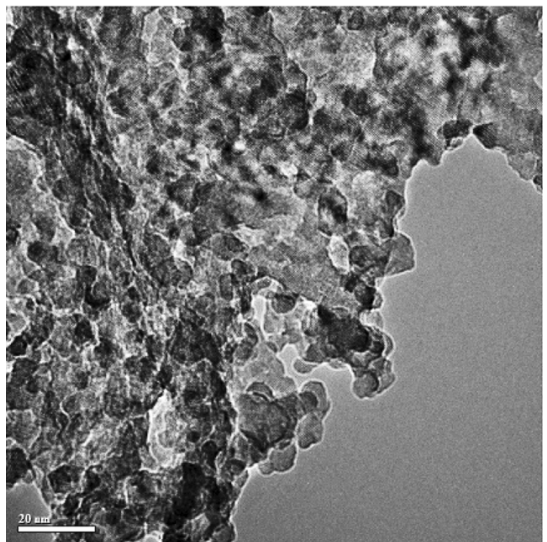

(b)

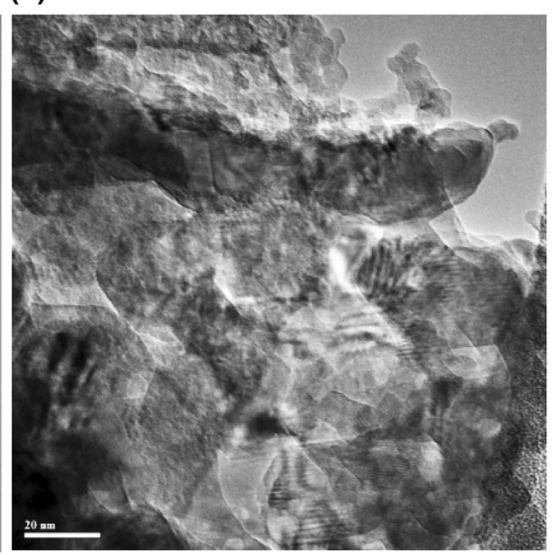

(d)

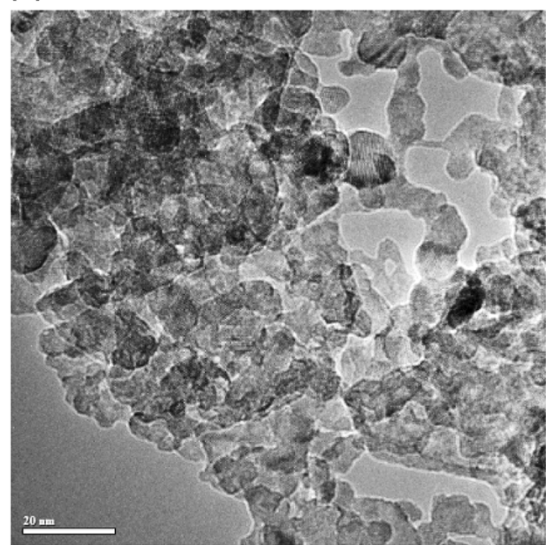

Fig. 3 TEM images of the samples: a $\mathrm{ZnO}$, b ZnO-Cr-1, $\mathbf{c} \mathrm{ZnO}-\mathrm{Cr}-2$, d ZnO-Cr-3

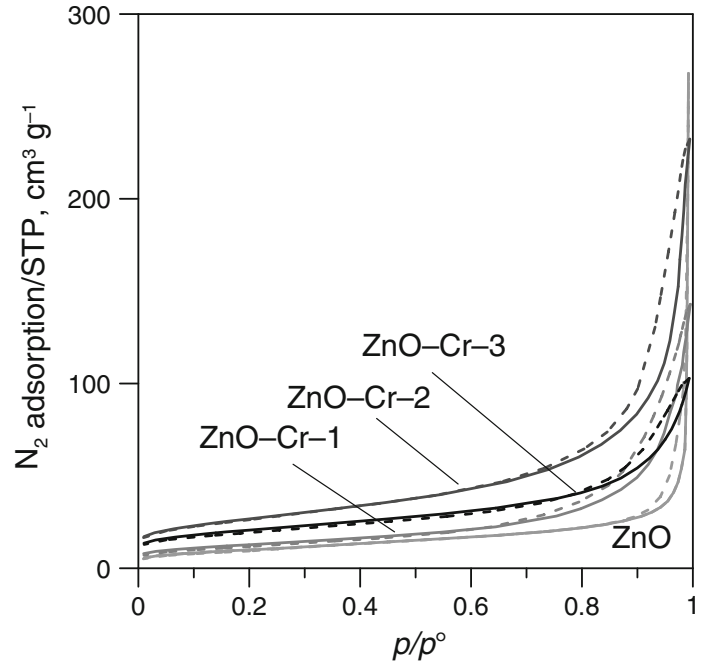

Fig. 4 Nitrogen adsorption-desorption isotherms of the samples

Accordingly, formation of $\mathrm{ZnO}-\mathrm{Cr}-\mathrm{x}$ high surface area materials can be connected with the presence of surface chromium phases, which may hinder fast growth and sintering of $\mathrm{ZnO}$ grains during precipitation and thermal treatment.

\section{Redox properties}

The temperature-programmed reduction curves of synthesized samples are presented in Fig. 5. No reduction peaks were detected below room temperature. The minor peak of hydrogen consumption for $\mathrm{ZnO}$ sample is observed at $250{ }^{\circ} \mathrm{C}$. Small and wide peaks are also visible above $550{ }^{\circ} \mathrm{C}$. These peaks can be attributed to the removal of surface oxygen by hydrogen. For chromium-modified zinc oxides, large irregular peaks are observed in the range of 200-350 ${ }^{\circ} \mathrm{C}$. Consumption of hydrogen is connected with reduction of $\mathrm{Cr}^{6+}$ to $\mathrm{Cr}^{3+}[26,27]$. The temperature of main reduction maximum is gradually moved from 301 to $306{ }^{\circ} \mathrm{C}$ with an increase of chromium content. The shape of TPR peaks indicates the presence of oxide phases of different metal-oxygen bond strength. All samples contain small amounts of more difficult to reduce chromium phases, probably dispersed and strongly interacted with $\mathrm{ZnO}$ 


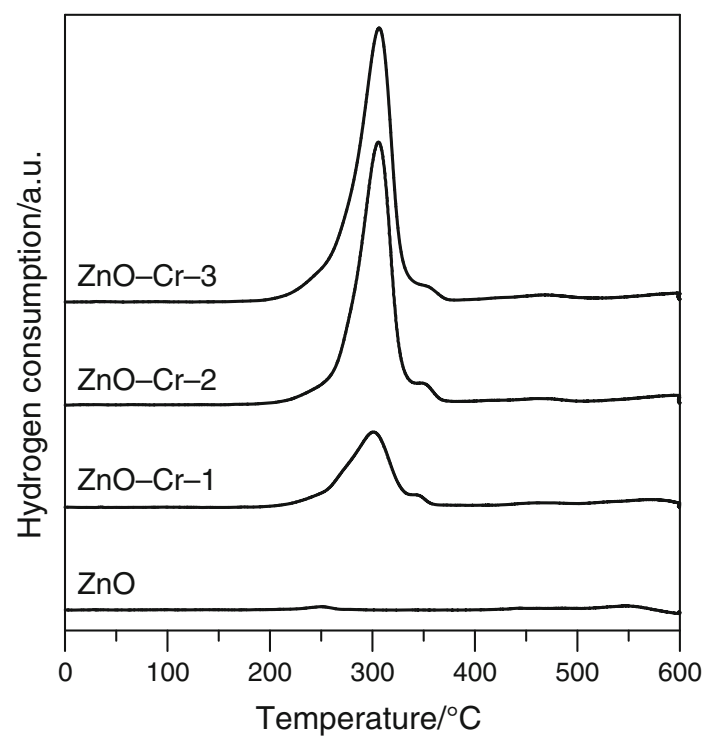

Fig. 5 Temperature-programmed reduction curves

species. TPR studies indicate that at least two types of adsorption sites can be present on the surface of chromiummodified zinc oxides, i.e. located on zinc oxide and assigned with chromium phases. The dual-site nature of the surface of oxides can be responsible for enhancement of some catalytic processes, e.g. related to simultaneous dehydrogenation/hydrogenation and reduction/oxidation processes.

Figure 6 shows temperature-programmed reduction curves, recorded after temperature-programmed oxidation of the obtained samples, carried out from $-70{ }^{\circ} \mathrm{C}$ to the suitable temperature: $100,200,300$ and $400{ }^{\circ} \mathrm{C}$, respectively. Very small hydrogen consumption was observed for $\mathrm{ZnO}$ (not shown here). Thermal treatment of chromiummodified oxides in the oxidative atmosphere at low temperatures leads to the increase of the oxidation state of $\mathrm{Cr}^{3+}$ ions, probably located in the surface region of nanoparticles. The extent of the changes of oxidation state of $\mathrm{Cr}^{3+}$ ions rises with an increase of the treatment temperature and can be connected with participation of subsurface or inner sites in redox processes. Such effects are being accompanied by the changes of reducibility-an increase of the size of TPR peaks and shift of maxima towards higher temperatures. The TPR peaks become more pronounced and the maxima appear at higher temperatures as chromium content is increased. Studies indicate that the course of surface processes over chromium-modified zinc oxides may depend on the composition of oxides and the reaction conditions, including temperature and the presence of compounds with reductive or oxidative properties in the reaction mixture.

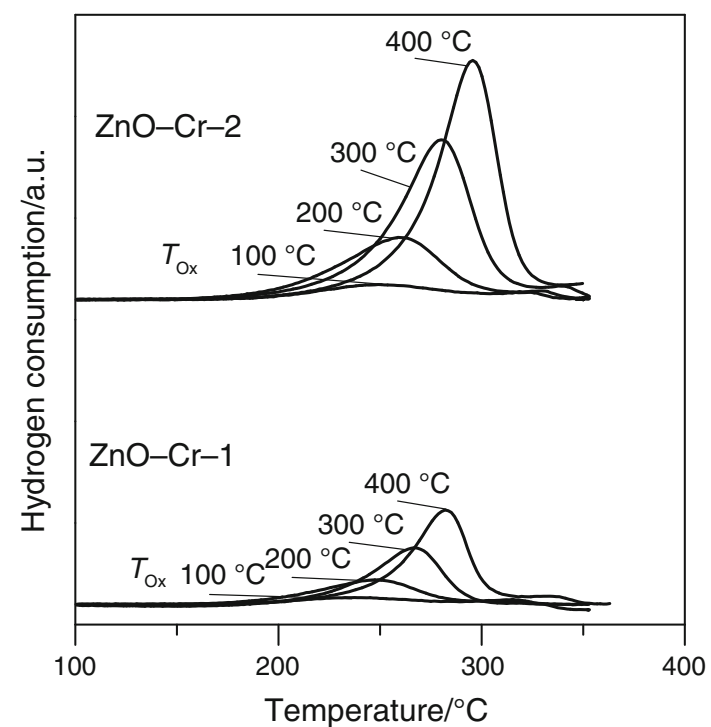

Fig. 6 Temperature-programmed reduction curves after oxidation of the samples at different temperatures $\left(T_{\text {ox. }}\right)$

\section{Methanol adsorption and desorption}

Methanol adsorption and temperature-programmed desorption have been frequently used for characterization of the surface of catalysts [33-35]. It is well-accepted opinion that methanol can be adsorbed dissociatively on the surface of oxides with the formation of methoxy species $\left(\mathrm{O}-\mathrm{CH}_{3}\right)$, and its further conversion depends on the properties of oxides and gas phase composition [35-37].

We have performed adsorption of methanol at $100{ }^{\circ} \mathrm{C}$ on the surface of pre-treated samples in the inert gas. The temperature-programmed desorption curves recorded by means of mass spectrometry are presented in Fig. 7. The concentration of selected major products, i.e. hydrogen $(\mathrm{m} /$ $e=2)$, carbon monoxide $(m / e=28)$ and carbon dioxide $(m / e=44)$, is displayed. The main products of methanol desorption from $\mathrm{ZnO}$ sample are carbon monoxide and hydrogen. Hydrogen is formed over $\mathrm{ZnO}$ sample above $150{ }^{\circ} \mathrm{C}$. The shape of hydrogen desorption peak is relatively complex and results from the overlying of few desorption peaks with maxima at about 250,300 and $340{ }^{\circ} \mathrm{C}$. The maximum of the large carbon monoxide peak is observed at around $340{ }^{\circ} \mathrm{C}$, while the maximum of very small carbon dioxide peak is visible at $300{ }^{\circ} \mathrm{C}$. The decomposition of methanol towards hydrogen and carbon dioxide occurs much easier over chromium-modified zinc oxides. The first small peak of hydrogen starts nearly at $100{ }^{\circ} \mathrm{C}$. Evolution of hydrogen occurs together with the formation of the small amounts of methanol, formaldehyde, water (not shown here) and larger amounts of carbon dioxide. The main peak of hydrogen is visible in the 


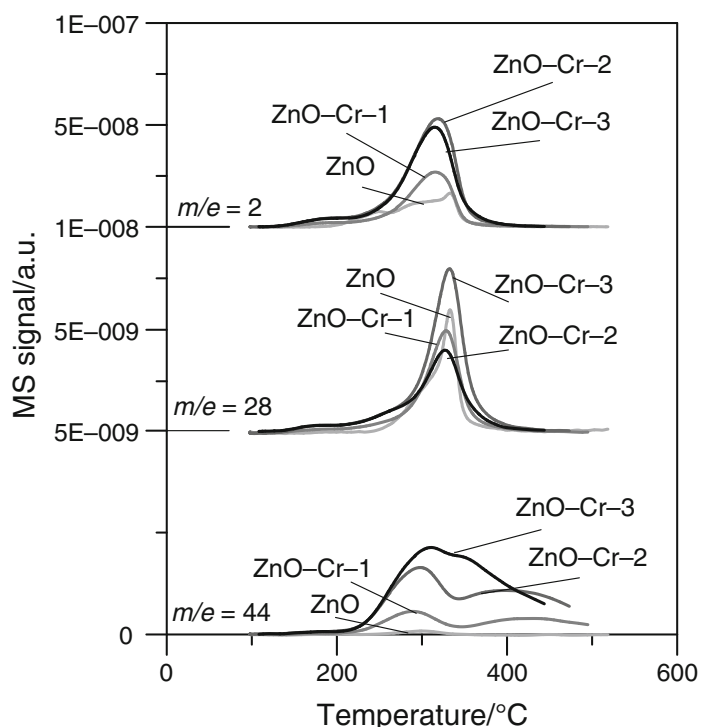

Fig. 7 MS-temperature-programmed desorption of methanol

temperature region of the evolution of carbon dioxide and then carbon monoxide.

DRIFTS spectra recorded during initial heating of calcined samples in the inert gas reveal the presence of hydroxyl groups bounded to different types of zinc and chromium sites (Fig. 8). In the case of $\mathrm{ZnO}$, well-visible vibration bands of $\mathrm{OH}$ groups are observed at 3688,3656 , $3619,3556,3433$ and $3379 \mathrm{~cm}^{-1}$. Physically adsorbed water, hydrogen-bonded and weaker hydroxyl groups are

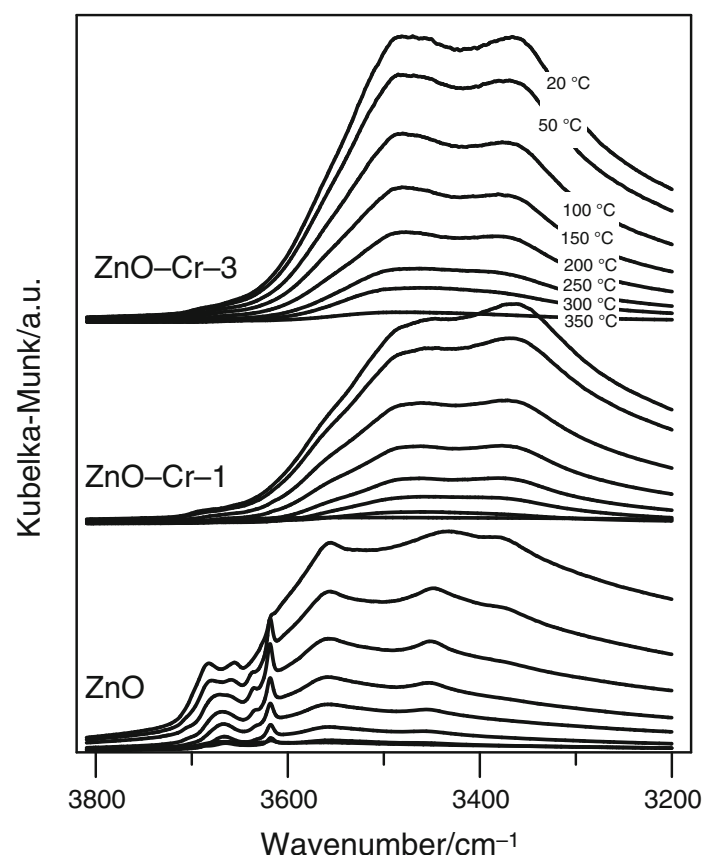

Fig. 8 DRIFTS spectra of the samples recorded at different temperatures during thermal treatment before adsorption of methanol removed during thermal treatment at low temperatures. Very strong hydroxyl groups with vibration bands, located at higher wavenumbers, remain on the surface of pretreated samples at high temperatures, even at $350{ }^{\circ} \mathrm{C}$. Different hydroxyl groups can be found on the surface of chromium-modified zinc oxides. The vibration bands in general are shifted to lower wavenumbers. The shift of stretching vibration bands towards lower wavenumbers can be ascribed to the $\mathrm{O}-\mathrm{H}$ bond strength decrease and the same to the increase of Brønsted acidity of $\mathrm{OH}$ groups. This effect can be explained by the decrease of the electronic density between oxygen and hydrogen atoms, caused by cation electron-withdrawing phenomena. The frequency of the stretching vibration bands can be also influenced by the local environment of the sites and mutual interaction between hydroxyl groups, especially in porous material. The bands of hydroxyls located at high wavenumbers are almost invisible. $\mathrm{ZnO}$ nanoparticles in chromium-modified oxides are much smaller than in pure $\mathrm{ZnO}$ sample. The surface is more energetically heterogeneous due to point defects and the presence of chromium oxide species.

DRIFTS studies evidence that the way of methanol adsorption and surface reactions are related to the number and the nature of surface sites (Fig. 9). Methanol is adsorbed on the surface of $\mathrm{ZnO}$ at $100{ }^{\circ} \mathrm{C}$ mainly via formation of methoxy species [35-37]. The disappearance of vibration of hydroxyl groups located at higher wavenumbers during adsorption may indicate formation of strongly bounded species. The asymmetric $v_{\mathrm{as}}\left(\mathrm{CH}_{3}\right)$ and symmetric $v_{\mathrm{s}}\left(\mathrm{CH}_{3}\right)$ stretching vibrations after flushing of methanol at $100{ }^{\circ} \mathrm{C}$ are observed at 2931 and $2820 \mathrm{~cm}^{-1}$, respectively. Slight peaks at 2888 and $2787 \mathrm{~cm}^{-1}$, with weak shoulder at $2911 \mathrm{~cm}^{-1}$, may indicate the presence of vibration bands of formate species $v(\mathrm{CH})$ adsorbed on the different $\mathrm{ZnO}$ planes [37-40]. In the fingerprint region (from 1700 to $650 \mathrm{~cm}^{-1}$ ), the most pronounced band is located at $1071 \mathrm{~cm}^{-1}$, which correspond to $v(\mathrm{CO})$ stretching vibrations in methoxy groups. Slight negative bands at 1504 and $1340 \mathrm{~cm}^{-1}$ can be ascribed to vibration bands of $v_{\mathrm{as}}(\mathrm{OCO})$ and $v_{\mathrm{s}}(\mathrm{OCO})$, related to the displacement of carbonate-like species.

The intensities of vibration bands of methoxy groups $v_{\text {as }}\left(\mathrm{CH}_{3}\right)$ and $v_{\mathrm{s}}\left(\mathrm{CH}_{3}\right)$, as well as formate groups $v(\mathrm{CH})$, are slowly decreased during heating of the samples in the inert gas. New vibration bands of $v(\mathrm{CH})$, located at 2970 and $2870 \mathrm{~cm}^{-1}$, are developed above $300{ }^{\circ} \mathrm{C}$. Simultaneously, the intensity of the band at $1071 \mathrm{~cm}^{-1}$ is decreased and shifted to $1056 \mathrm{~cm}^{-1}$, which is connected with the removal of methoxy groups of different thermal stability. Development of new bands at 1580, 1365 and $1380 \mathrm{~cm}^{-1}$, assigned to asymmetric and symmetric stretching vibrations $v_{\mathrm{as}}(\mathrm{OCO}), v_{\mathrm{s}}(\mathrm{OCO})$, indicates gradual transformation of methoxy to formate species. The increase of intensity of 

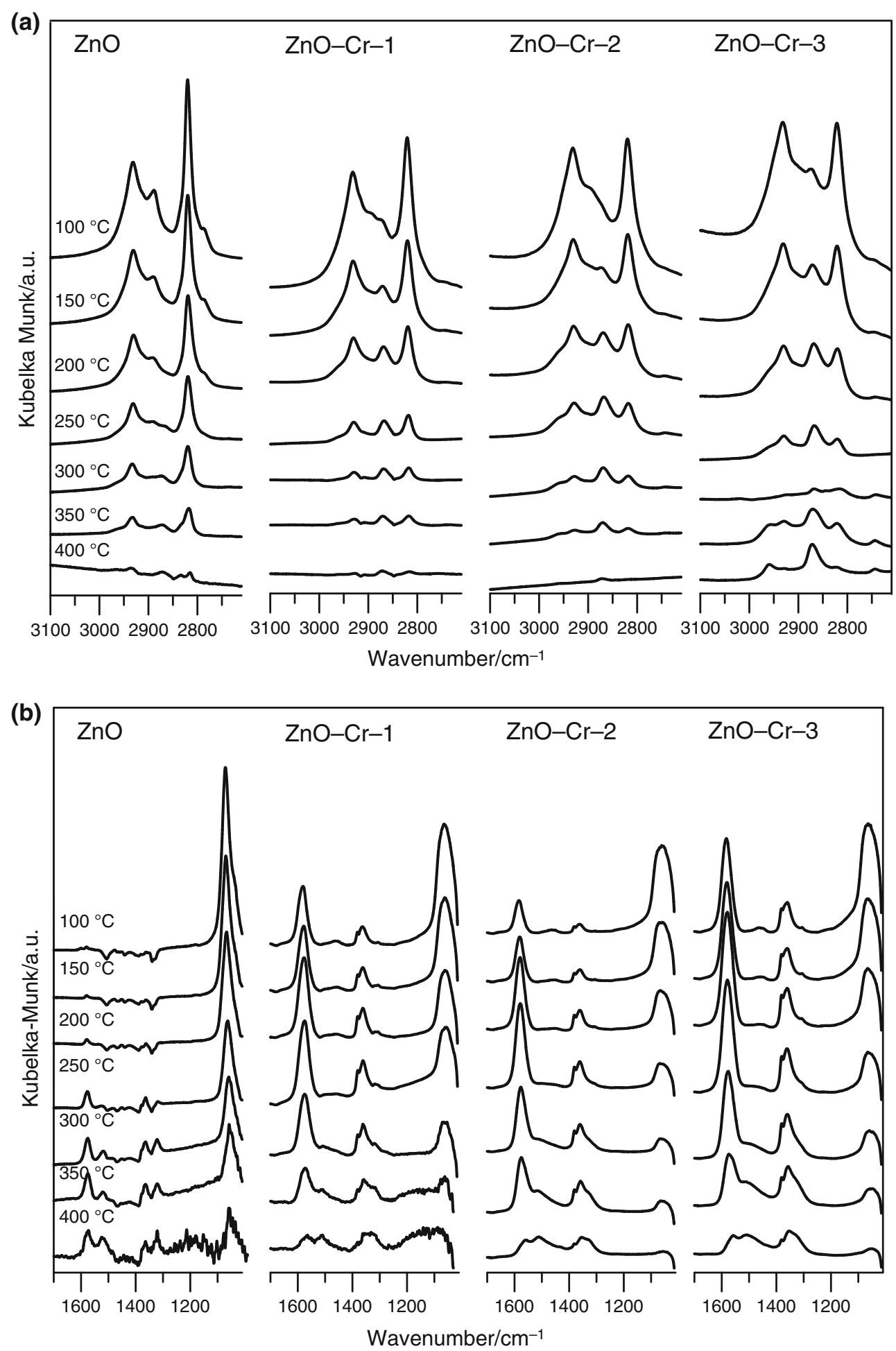

Fig. 9 DRIFTS spectra of the samples recorded at different temperatures during temperature-programmed desorption of methanol; a high wavenumber region, b fingerprint region

the bands at 1516 and $1321 \mathrm{~cm}^{-1}$ above $250{ }^{\circ} \mathrm{C}$ is due to the formation of carbonate-like species.

During adsorption of methanol over chromium-modified zinc oxides, similar phenomena connected with the decrease of intensity of hydroxyl bands located at higher wavenumbers are visible. The asymmetric $v_{\mathrm{as}}\left(\mathrm{CH}_{3}\right)$ and symmetric $v_{\mathrm{s}}\left(\mathrm{CH}_{3}\right)$ band vibrations of methoxy groups are observed at almost the same wavenumbers as for $\mathrm{ZnO}$ 
sample. Strong band of formate species, observed for $\mathrm{ZnO}$ at $2888 \mathrm{~cm}^{-1}$ after flushing of methanol at $100{ }^{\circ} \mathrm{C}$, appears as weak shoulder for modified oxides. Moreover, new vibration band of $v(\mathrm{CH})$ is visible at $2870 \mathrm{~cm}^{-1}$. The intensity of this band strongly increases with an increase of desorption temperature. The pronounced changes of the way of methanol desorption are observed in the fingerprint region. Modification of zinc oxide with chromium facilitates formation of formate species at $100{ }^{\circ} \mathrm{C}$. Strong stretching $v_{\text {as }}(\mathrm{OCO})$ and $v_{\mathrm{s}}(\mathrm{OCO})$ vibration bands at 1580 , 1361 and $1381 \mathrm{~cm}^{-1}$ are detected. The $\mathrm{C}-\mathrm{O}$ stretching vibration bands $v_{\mathrm{s}}(\mathrm{CO})$ of methoxy groups are located at around $1055 \mathrm{~cm}^{-1}$. The intensity of methoxy groups decreases much easier than formates during temperature increase. The transformation of methoxy to formate and carbonate species is connected with dehydrogenation and oxidation surface processes. Such reactions may take place with participation of surface oxygen or hydroxyl groups. The enhancement of the transformation of the species over chromium-modified oxides can be connected with the presence of labile surface oxygen and the changes of the oxidation state of chromium $\left(\mathrm{Cr}^{3+} \leftrightarrow \mathrm{Cr}^{6+}\right)$. Similar phenomena may improve catalytic activity and selectivity of copper or noble metal catalysts containing chromiummodified zinc oxide supports. Thus, formation of formates as intermediate species on the active metal sites, in such reactions as carbon dioxide hydrogenation or steam reforming of methanol, can be reinforced by the support.

\section{Conclusions}

Co-precipitation method was used for preparation of chromium-modified zinc oxides. The contents of chromium were varied from 3.33 to 17.1 mass $\%$. We have shown that the presence of chromium influenced not only the size of particles, but also the structural properties of oxides and the chemical nature of the surface sites. The decrease of the mean crystallite size of $\mathrm{ZnO}$ was observed with an increase of chromium content. The specific surface area increased with the increase of chromium content up to 13 mass\%. Chromium ions were partially incorporated to $\mathrm{ZnO}$ structure. Dispersed spinel $\left(\mathrm{ZnCr}_{2} \mathrm{O}_{4}\right)$ and chromium zinc oxide $\left(\mathrm{ZnO} \cdot \mathrm{CrO}_{3}\right)$ species were also detected. The possibility of the changes of the oxidation state of chromium in the reaction conditions was inferred. It was stated that methanol was adsorbed on the surface of obtained zinc oxide at $100{ }^{\circ} \mathrm{C}$ mainly via formation of methoxy species, and the main products of methanol desorption at higher temperatures were carbon monoxide and hydrogen. The presence of chromium in the prepared materials facilitated direct formation of formate species at low temperatures $\left(100{ }^{\circ} \mathrm{C}\right)$ and their transformation to hydrogen and carbon dioxide at elevated temperatures.
Acknowledgements This work was carried out in part within the framework of European Union's Seventh Framework Programme for the Fuel Cells and Hydrogen Joint Technology Initiative under IRMFC Grant Agreement No. 325358. The research was carried out with the equipment purchased thanks to the financial support of the European Regional Development Fund in the framework of the Polish Innovation Economy Operational Program (Contract no. POIG.02.01.00-06-024/09 Center of Functional Nanomaterials).

Open Access This article is distributed under the terms of the Creative Commons Attribution 4.0 International License (http://crea tivecommons.org/licenses/by/4.0/), which permits unrestricted use, distribution, and reproduction in any medium, provided you give appropriate credit to the original author(s) and the source, provide a link to the Creative Commons license, and indicate if changes were made.

\section{References}

1. Moezzi A, McDonagh AM, Cortie MB. Zinc oxide particles: synthesis, properties and applications. Chem Eng J. 2012;185186:1-22.

2. Özgür Ü, Alivov YI, Liu C, Teke A, Reshchikov MA, Doğan S, Avrutin V, Cho SJ, Morkoç H. A comprehensive review of $\mathrm{ZnO}$ materials and devices. J Appl Phys. 2005;98:1-103.

3. Wang ZL. Zinc oxide nanostructures: growth, properties and applications. J Phys Condens Matter. 2004;16:R829-58.

4. Willander M, Nur O, Zhao QX, Yang LL, Lorenz M, Cao BQ, Pérez JZ, Czekalla C, Zimmermann G, Grundmann M, Bakin A, Behrends A, Al-Suleiman M, El-Shaer A, Che Mofor A, Postels B, Waag A, Boukos N, Travlos A, Kwack HS, Guinard J, Dang DLS. Zinc oxide nanorod based photonic devices: recent progress in growth, light emitting diodes and lasers. Nanotechnology. 2009;20:332001-3320040.

5. Rodnyi PA, Khodyuk IV. Optical and luminescence properties of zinc oxide (review). Opt Spectrosc. 2011;111:776-85.

6. Pillai SC, Kelly JM, Ramesh R, McCormack DE. Advances in the synthesis of $\mathrm{ZnO}$ nanomaterials for varistor devices. J Mater Chem C. 2013;1:3268-81.

7. Wei A, Pan L, Huang W. Recent progress in the $\mathrm{ZnO}$ nanostructure-based sensors. Mater Sci Eng B. 2001;176:1409-21.

8. Arya SK, Saha S, Ramirez-Vick JE, Gupta V, Bhansali S, Singhe SP. Recent advances in $\mathrm{ZnO}$ nanostructures and thin films for biosensor applications: review. Anal Chim Acta. 2012;737:1-21.

9. Liu C, Yun F, Morkoç H. Ferromagnetism of $\mathrm{ZnO}$ and GaN: a review. J Mater Sci Mater Electron. 2005;16:555-97.

10. Ahmad M, Ahmed E, Zhang Y, Khalida NR, Xu J, Ullah M, Hong Z. Preparation of highly efficient Al-doped $\mathrm{ZnO}$ photocatalyst by combustion synthesis. Curr Appl Phys. 2013;13: 697-704.

11. Kołodziejczak-Radzimska A, Jesionowski T. Zinc oxide -from synthesis to application: a review. Materials. 2014;7:2833-81.

12. Lloyd L. Handbook of industrial catalysts. New York: Springer Science \& Business Media; 2011.

13. Yang Y, Xie W. Soybean oil transesterification over zinc oxide modified with alkali earth metals. Fuel Process Technol. 2007;88:631-8.

14. Kumar BV, Naik HSB, Girija D, Kumar BV. ZnO nanoparticle as catalyst for efficient green one-pot synthesis of coumarins through Knoevenagel condensation. J Chem Sci. 2011;123: $615-21$.

15. Liu XM, Lu GQ, Yan YF, Beltramini J. Recent advances in catalysts for methanol synthesis via hydrogenation of $\mathrm{CO}$ and $\mathrm{CO}_{2}$. Ind Eng Chem Res. 2003;42:6518-30. 
16. Sá S, Silva H, Brandãoa L, Sousa JM, Mendes A. Catalysts for methanol steam reforming - a review. Appl Catal B Environ. 2010;99:43-57.

17. Maroto-Valer MM, Song C, Soong Y. Environmental challenges and greenhouse gas control for fossil fuel utilization in the 21st century. New York: Springer Science \& Business Media; 2002.

18. Avgouropoulos G, Schlicker S, Schelhaas K-P, Papavasiliou J, Papadimitriou KD, Theodorakopoulou E, Gourdoupi N, Machocki A, Ioannides T, Kallitsis JK, Kolb G, Neophytides S. Performance evaluation of a proof-of-concept $70 \mathrm{~W}$ internal reforming methanol fuel cell system. J Power Sources. 2016;307:875-82.

19. Bergeret G, Gallezot P. In: Ertl G, Knozinger H, Weitkamp J, editors. Handbook of heterogeneous catalysis. Weinheim: VCH; 1997. p. 439.

20. Lowell S, Shields JE, Thomas MA, Thommes M. Characterization of porous solids and powders: surface area, pore size and density. Berlin: Kluwer Academic Publishers; 2004.

21. Liu Y, Yang Y, Guan Q, Liu H, Yang L, Zhang Y, Wang Y, Wei M, Liu X, Fei L, Cheng X. Intrinsic ferromagnetic properties in Cr-doped $\mathrm{ZnO}$ diluted magnetic semiconductors. J Solid State Chem. 2011;184:1273-8.

22. Shannon RD. Revised effective ionic radii and systematic studies of interatomic distances in halides and chalcogenides. Acta Cryst. 1976;A32:751-67.

23. Vaccari A. Clays and catalysis: a promising future. Appl Clay Sci. 1999;14:161-98.

24. Rives V, Ulibarri MA. Layered double hydroxides (LDH) intercalated with metal coordination compounds and oxometalates. Coord Chem Rev. 1999;181:61-120.

25. Kloprogge JTh, Hickey L, Frost RL. The effect of varying synthesis conditions on zinc chromium hydrotalcite: a spectroscopic study. Mater Chem Phys. 2005;89:99-109.

26. Fuda K, Suda K, Matsunaga T. Oxidation of $\mathrm{Cr}(\mathrm{III})$ to $\mathrm{Cr}(\mathrm{VI})$ species during the thermal decomposition process of $\mathrm{Zn} / \mathrm{Cr}$-layered double hydroxide carbonate. Chem Lett. 1993;22:1479-82.

27. Arco M, Rives V, Trujillano R, Malet P. Thermal behaviour of $\mathrm{Zn}-\mathrm{Cr}$ layered double hydroxides with hydrotalcite-like structures containing carbonate or decavanadate. J Mater Chem. 1996;6:1419-28.

28. Naidu SR, Banerjee AK, Ganguli NC, Sen SP. Stoichiometric modifications of $\mathrm{ZnO}-\mathrm{Cr}_{2} \mathrm{O}_{3}$ catalyst system in oxidizing and reducing atmospheres. J Res Inst Catal. 1973;21:172-86.
29. Errani E, Trifiro F, Vaccari A, Richter M, Del Pierro G. Structure and reactivity of $\mathrm{Zn}-\mathrm{Cr}$ mixed oxides. Role of non-stoichiometry in the catalytic synthesis of methanol. Catal Lett. 1989;3:65-72.

30. Sing KSW. Reporting physisorption data for gas/solid systems. Pure Appl Chem. 1982;54:2201-18.

31. Maldonado A, Mallén-Hernández SA, Vega-Pérez J, de la L Olvera M, Tirado-Guerra S. Chromium doped zinc oxide thin films deposited by chemical spray used in photo-catalysis and gas sensing. Rev Mex Fis. 2009;55:90-4.

32. Tajizadegan H, Heidary A, Torabi O, Golabgir MH, Jamshidi A. Synthesis and characterization of $\mathrm{ZnCr}_{2} \mathrm{O}_{4}$ nanospinel prepared via homogeneous precipitation using urea hydrolysis. Int J Appl Ceram Technol. 2015;4:1-6.

33. Tatibouët JM. Methanol oxidation as a catalytic surface probe. Appl Catal A Gen. 1997;148:213-52.

34. Badlani M, Wachs IE. Methanol: a "smart" chemical probe molecule. Catal Lett. 2001;75:137-49.

35. Vargas MAL, Busca G, Costantino U, Marmottini F, Montanari T, Patrono P, Pinzari F, Ramis G. An IR study of methanol steam reforming over ex-hydrotalcite $\mathrm{Cu}-\mathrm{Zn}-\mathrm{Al}$ catalysts. J Mol Catal A Chem. 2007;266:188-97.

36. Strunk J, Kähler K, Xia X, Muhler M. The surface chemistry of $\mathrm{ZnO}$ nanoparticles applied as heterogeneous catalysts in methanol synthesis. Surf Sci. 2009;603:1776-83.

37. Kähler K, Holz MC, Rohe M, Strunk J, Muhler M. Probing the reactivity of $\mathrm{ZnO}$ and $\mathrm{Au} / \mathrm{ZnO}$ nanoparticles by methanol adsorption: a TPD and DRIFTS study. Chem Phys Chem. 2010;11:2521-9.

38. Ueno A, Onishi T, Tamaru K. Reaction intermediates in methyl alcohol decomposition on ZnO. Trans Faraday Soc. 1971;67: 3585-9.

39. Shido T, Iwasawa Y. Reactant-promoted reaction mechanism for water-gas shift reaction on $\mathrm{ZnO}$, as the genesis of surface catalysis. J Catal. 1991;129:343-55.

40. Fujita S, Ito H, Takezawa N. Remarks on the assignments of temperature programmed desorption peaks for the surface species formed on $\mathrm{Cu} / \mathrm{ZnO}$ and $\mathrm{ZnO}$ in the methanol synthesis from $\mathrm{CO}$. Catal Lett. 1995;33:67-74. 